\title{
SEED MYCOFLORA OF Lens culinaris MEDDIK. FROM DIFFERENT STORAGE CONDITIONS AND IN-VITRO INHIBITION USING PLANT EXTRACTS
}

\author{
Roshan Chhetri and Sanjay Kumar Jha* \\ Central Department of Botany \\ Tribhuvan University, Kirtipur, Kathmandu, Nepal \\ Email: roshanchhetri27@gmail.com, *j.sanjay99@yahoo.com
}

\begin{abstract}
Nine hundred sixty seeds of lentils (Lens culinaris) from three different storage sources were tested for seed fungi using Potato Dextrose Agar (PDA) and Blotter technique. Thirty five different fungi were isolated, PDA method being better than Blotter technique. Seeds from traditional village storage were found to be more infested with fungi than source local market and source Nepal Agricultural Research Centre (NARC). The fungal infestation on seeds from village storage was $49.37 \%$, source NARC was $44.37 \%$ and source local market was $30.31 \%$. Aspergillus flavus, Aspergillus niger, Alternaria alternata, Penicillium chrysogenum and Fusarium oxysporum were the fungi having higher incidence and frequency. Surface disinfection by $2 \% \mathrm{NaOCl}$ reduced the fungal incidence and frequency. The aqueous extract of three plants viz, Ageratum houstonianum, Eclipta prostrata and Vitex negundo at $25 \%, 50 \%$ and $100 \%$ concentration were assessed in-vitro for antifungal activity against Alternaria alternata, Aspergillus niger, Chaetomium funicola and Fusarium oxysporum. Among these fungi, Alternaria alternata was best controlled by Ageratum houstonianum; Aspergillus niger by Eclipta prostrata; Fusarium oxysporum by Vitex negundo and Ageratum houstonianum. The inhibition increased from lower concentration (25\%) to higher (100\%).
\end{abstract}

Key words: Seed-borne fungi, Seeds from different sources.

\section{INTRODUCTION}

Lentil is a leading winter pulse crop of Nepal (MOAD 2012). It is a high value crop, and also has a high potentiality of export to other countries (Neupane et al. 2013). It is also the largest exported item among agricultural commodities from Nepal with a share of about $2.3 \%$ of total national export and about $3.1 \%$ of the total world export (ITC 2010). Thus for the protection of such valued pulse is very important during post-harvest as lentils are attacked by relatively few pathogens as compared to other pulses in field (Khan et al. 1984). Presence or absence of seed-borne fungi on seed surface is one of the important aspects that determine the quality of seeds. During hot, humid conditions due to improper or bad storage management, a number of storage fungi members belonging to Aspergillus and Penicillium spp. infest the seeds (Ghosh et al. 1981). The deterioration of stored seed becomes faster if the 
seeds are not properly dried and the moisture is not controlled (Bass 1973 and Delouche et al. 1973). Many factors are responsible for seeds longevity in storage including moisture content, temperatures, relative humidity, initial viability, stage of maturity at harvest, storage gas and initial moisture content of seed entering into the storage (Harrington 1972 and Barton 1961). Storage fungi gets associated and contaminate the seeds later after harvest (Christensen and Kaufmann 1969) but may be present as contamination within the seed pericarp or seed coat (Warnock and Preece 1971). Different contaminants have different and varying degree to spread within a seed lot or storage condition and ways in which seeds are collected. Aspergillus niger, A. flavus, Alternaria alternata, Penicillium $\mathrm{sp}$, Cladosporium sp. etc are the most frequently encountered fungi during storage condition (Agrios 2005). Therefore, seed-borne fungi are of considerable importance due to their influence on the overall health, germination and final crop stand in the field (Baka 2014). The infected seeds may fail to germinate or transmit disease to seedling and seedling to growing plant that may produce even large quantity of infested seeds (Baka 2014). Seed borne fungi are predominantly responsible for seed deterioration in storage condition under conducive environment (Lutey and Christensen 1963, Christensen and Kaufmann 1965, Sharma et al. 1988, Pandey et al. 1991, Shah and Jain 1993) and reduce the germination capacity of stored seeds.

Seeds can be contaminated by the mycotoxins secreted by fungi growing on the seeds. Mycotoxins, due to its adverse impacts on human health, animal productivity and trade have been a global issue (Khlangwiset et al. 2011). So, control of seed borne fungi needs to be done for the increase in percentage of seed germination and grain yield.

Synthetic chemicals used to control seed-borne fungi are risky and to some extent restricted due to their possible carcinogenicity, high and acute toxicity, long degradation periods and environmental pollutions (Baka et al. 2014). So, the use of compounds of biological origin as extract may be alternative to the fungicides due to their rich source of bioactive compounds like phenols, flavonoids, quinons, tannins, alkaloids, saponins and sterols (Burt 2004). As these compound can be active against fungal pathogens being biodegradable to non-toxic and potentially suitable for use in Integrated Pest Management (IPM) programs and become a new and safe class of disease management tools (Baka 2014). Some phytochemicals of plant origin have been formulated as botanical pesticides and are used successfully in Integrated Pest Management Programs (Schmutter 1990).

The present investigation aims to isolate and compare the effect of storage condition on seed mycoflora and the antifungal activity of the aqueous extract of some plants against some predominant fungi.

\section{MATERIALS AND METHODS}

Seeds sample collection: Seeds from three different storage conditions were collected: (i) Nepal Agricultural Research Centre (NARC) storage, Khumaltar, Laltipur, (ii) Local Market Storage and (iii) Traditional Village Storage.

Fungi isolation: Fungi isolation was done using Standard Blotter Technique (De Tempe 1953) and Agar Plate Method (Muskett 1948).

Standard Blotter Technique (De Tempe 1953): In this method, the seeds were plated in the sterilized petridishes on three layers of moistened and sterilized blotters. For this at first the blotters were cut into appropriate size and autoclaved at $121^{\circ} \mathrm{C}$ for $30 \mathrm{~min}$ at $15 \mathrm{psi}$. The petridishes were also sterilized in a hot air oven at $160^{\circ} \mathrm{C}$ for two hours. Then the sterile blotters were placed within petridishes aseptically followed by moistening 
them with sterile water removing the excess water later on. The excess water was removed to avoid extra moisture that could check or minimize the fungal grow on blotters. The dishes were then plated with eight sterilized and non-sterilized seeds separately five replica for each treatment. The seeds were placed at equal distance from each other. For sterilization process, seeds were treated with $2 \% \mathrm{NaOCl}$ for two minutes and were washed with sterile water for three times for rinsing. Finally the petridishes were incubated at $22 \pm 2^{\circ} \mathrm{C}$.

Agar Plate Method (Muskett 1948): In this method, seeds were placed in sterilized petridishes containing synthetic Potato Dextrose Agar media at the recommended ratio of $39 \mathrm{~g} / 1000 \mathrm{ml}$. The media was sterilized in autoclave at $121^{\circ} \mathrm{C}$ and 15 psi for $30 \mathrm{~min}$. Prepared media was then allowed to cool at around $45^{\circ} \mathrm{C}$ and added with antibiotic to protect the media from bacterial contamination. About $10 \mathrm{ml}$ of media was poured in the dishes aseptically near the Bunsen burner to avoid fungal contaminations. Then sterilized and non-sterilized seeds were placed aseptically on solidified media eight in number at equal distance from each other with five replicas of each treatment. Finally the plates were sealed with cello tape and incubated at $22 \pm 2^{\circ} \mathrm{C}$

All the plates were labeled as 'USS' for unsterilized seeds and 'SS' for surface sterilized seeds and were incubated at a controlled temperature $22 \pm 2^{\circ} \mathrm{C}$. Seed mycoflora were observed after seven days for Agar Plate media and 20-30 days for Blotter media.

Plant collection: Mature and disease free leaves of Ageratum houstonianum, Eclipta prostrata, Vitex negundo were used for the extraction process. Ageratum houstonianum and Vitex negundo leaves were collected on April 2016 but Eclipta prostrata on May 2016. Selected plants were locally available in sufficient quantities at the collection place.

Source of crude plant extract: The extract was prepared using sterile distilled water following the method described by Oyagade et al. (1999) with slight modification. The water extract was prepared by mixing $25 \mathrm{~g}$ of finely blended dried leaves in $125 \mathrm{ml}$ of distilled water. The mixture was then stirred for $30 \mathrm{~min}$ and then was allowed to stand for $24 \mathrm{~h}$. It was then filtered through triple layer of sterile muslin cloth followed by filtering the filtrate with Whattman filter paper. This final extract was treated and used as a crude extract which was stored in the refrigerator at $4^{\circ} \mathrm{C}$ until use. Different concentration of extract was prepared by serial dilution method. Three different concentrations $25 \%, 50 \%$ and $100 \%$ were made.

Test fungi: Test fungi were selected on the basis of their dominancy during isolation. Alternaria alternata, Aspergillus niger, Chaetomium funicola, Fusarium oxysporum. The culture of test fungi was maintained on PDA medium, which was served as the test fungi for antifungal activity.

Fungi culture and preservation: The fungi isolated from seeds were cultured on petriplates using PDA which was then again sub cultured to get pure fungi culture. The sub culture isolates were kept and preserved using slant prepared from PDA inside test tube. The slant was prepared for the future use of fungi for identification as well as for anti-fungal assay.

Antifungal assay: The following combination of PDA and extract was done for the assessment of poison food technique (Grover and Moore 1962). The fungitoxic effect of plants was recorded in terms of percent inhibition of mycelial growth. 


\begin{tabular}{cccc}
\hline Concentration $(\boldsymbol{\%})$ & PDA $(\mathbf{m l})$ & Extract $(\mathbf{m l})$ & Water $(\mathbf{m l})$ \\
\hline 100 & 10 & 5 & 0 \\
50 & 10 & 2.5 & 2.5 \\
25 & 10 & 1.25 & 3.75 \\
Control & 10 & 0 & 5.0 \\
\hline
\end{tabular}

The 7 days old culture of fungi was used against the poisoned media to test the efficacy of extract. After the solidification of the media, the young growing fungal mass of equal size for all petriplates was aseptically inoculated upside down at the centre and incubated at $22 \pm 2^{\circ} \mathrm{C}$.

The average diametre of the fungal colonies were measured on the $7^{\text {th }}$ day of incubation and percentage of mycelial growth inhibition was calculated (Rao and Shrivastava 1994).

Mycelial growth inhibition $(\%)=\frac{\mathrm{Gc}-\mathrm{Gt}}{\mathrm{Gc}} \times 100$ Where,

$\mathrm{G}_{\mathrm{c}}=$ Growth of mycelial colony in control set

$\mathrm{G}_{\mathrm{t}}=$ Growth of mycelial colony in treatment set

Fungal frequency was calculated using following formula:

Frequency of occurrence $(\%)=$

$$
\frac{\text { No. of seeds on which fungal species occurs }}{\text { Total No. of seeds }} \times 100
$$

\section{RESULTS AND DISCUSSION}

Fungi isolation: All together 35 different fungi were isolated using 960 lentil seeds from three different sources, seeds from village source being more infested with fungi as compared to other sources.

The fungal presence and frequency was more in seeds from village source. The frequency was $49.37 \%$ followed by seed from local market source $44.37 \%$ and seed source NARC $30.31 \%$. This shows the lentil seeds are heavily infested with the fungi making the seed storage vulnerable toward the storage process.

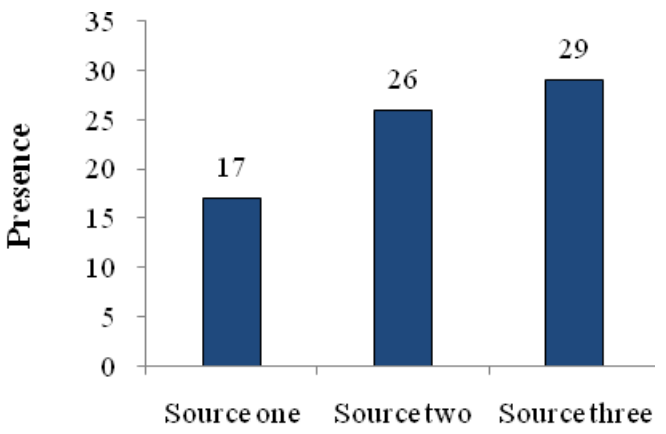

Seed Source

Fig. 1. Incidence of fungi on seed source (NARC, local market and traditional village).

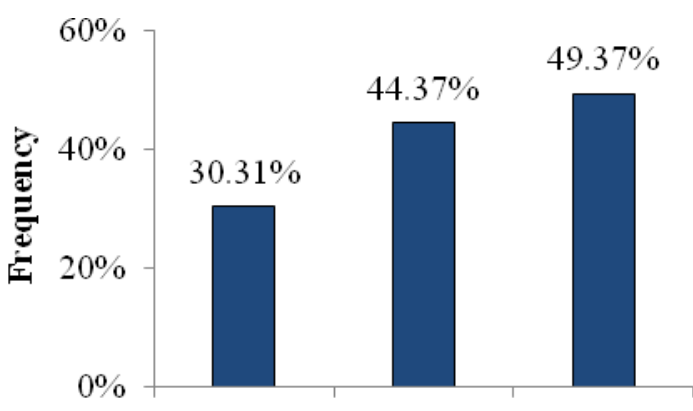

Source one Sourcetwo Sourcethree

Seed Source

Fig. 2. Frequency of fungi on seed source (NARC, local market and traditional village).

Raju (2013) tested lentil seeds from four types of storage containers and two storage conditions and isolated Fusarium oxysporum (3.50\%), Aspergillus niger (19.75\%), Aspergillus flavus (5.75\%), Penicillium sp. (2.50\%) and Rhizopus sp. $(2.89 \%)$. From two types of storage conditions (three months after storage, six months after storage) and four types of storage containers (tin

ECOPRINT VOL 23, 2016 
pot, polythene bag, paper bag and gunny bag) it was observed that the percentage germination and normal seedlings were found decreased as the storage time increased.

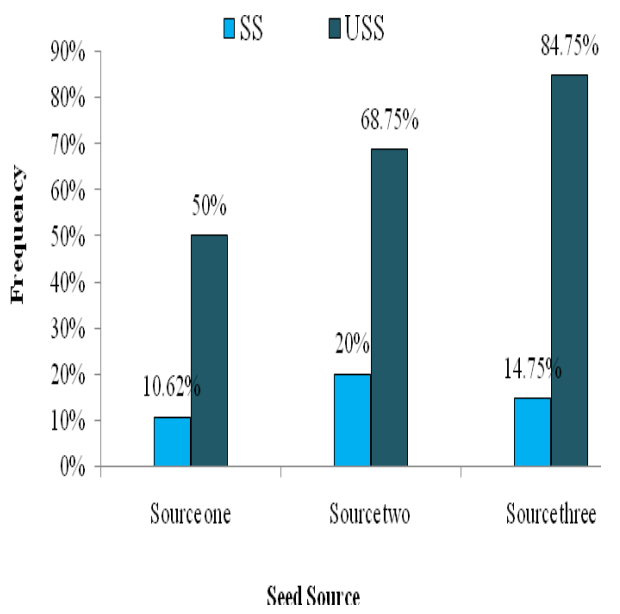

Fig. 3. Frequency of fungi on treated and untreated seeds.

The frequency of fungi was more in seeds treated with $2 \%$ Sodium hypochlorite than untreated seeds in all three seed sources. The difference was very high in all three cases; this suggests that the seeds were heavily infested with saprophytic fungi like genus Aspergillus, Penicillium, Rhizopus, etc. These are the fungi with frequency higher than other isolated fungi.

Seed samples were collected from three different places all having different storage and field condition. This might be a cause for variation in the fungal presence and frequency in three storage condition types. Fungi were more prominent in seeds collected from village source followed by sources local market and NARC. The fungal dominancy in seeds from village might be due to the improper traditional storage condition during post- harvest management and noncommercial agricultural practice. Non-commercial agricultural practice means the farmers do not target towards the income generation from lentil production and they do not use fungicides at proper time resulting in the seeds harboring the pathogens. They just cultivate the crop for house consumption. Another possible reason could be the adhered soil particle to seeds that might not have been completely removed during seed rising and washing at a time of incubation. Similarly, the reason behind least fungal incidence and prevalence in seed storage from NARC might be due to the seeds treatment with fungicides, healthy storage condition, fungicides used during field and healthy seeds during sowing, the least fungal case also could have due to seeds produced from the resistant varieties.

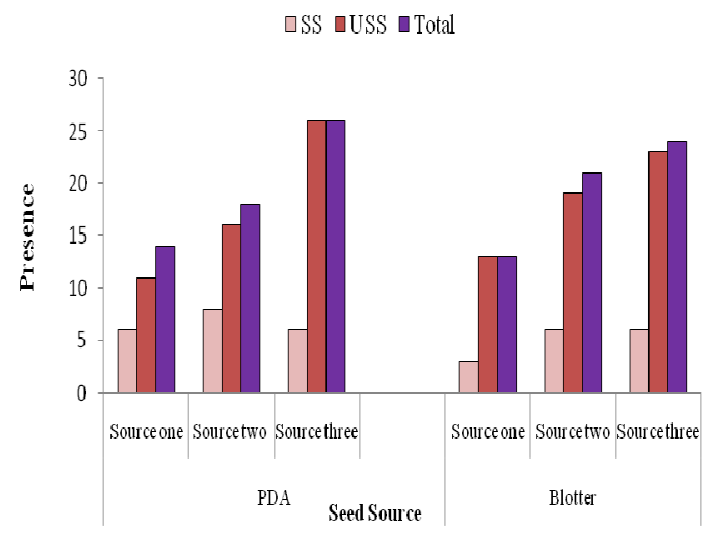

Fig. 4. Presence of fungi from different seed source.

Among the isolated fungi, the incidence or presence was more in un-sterilized seeds as compared to seeds treated with $2 \% \mathrm{NaOCl}$.

In this study, PDA was ideal for both the saprophytic and pathogenic fungi, but blotter method was considered excellent for mycelial growth, conidial sporulation as well as development of signs of infection produced by pathogens. In the same way, PDA method was considered excellent for mycelial growth, conidial sporulation as well as development of signs of isolation (Nasir 2003, Nik 1980) in soybean, (Embaby et al. 2013, Rathod et al. 2012, Embaby and Mona 2006) in some legume seeds. 


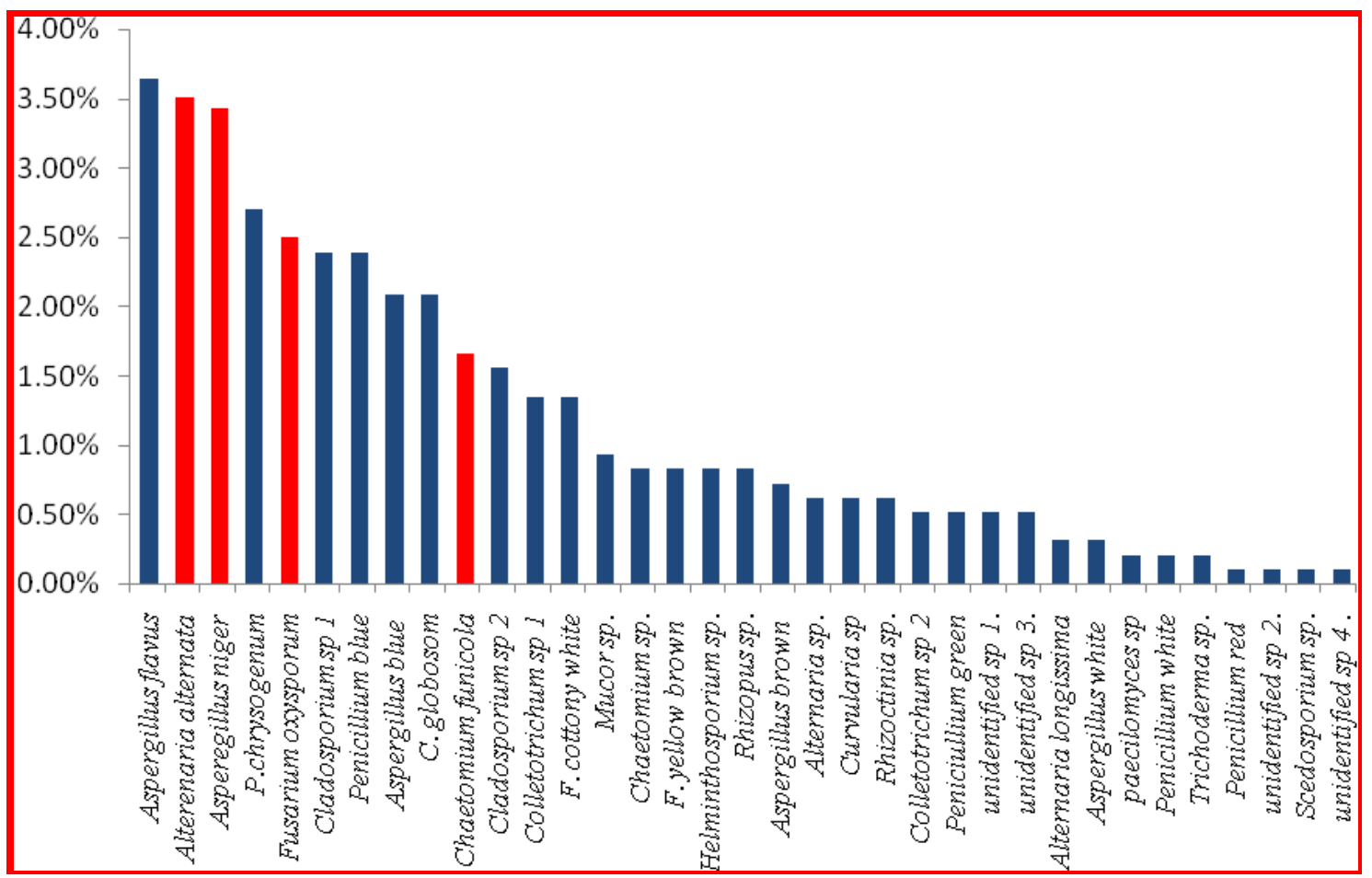

Fig. 5. Overall frequency of individual fungi.

Table 1. Mycelial growth inhibition by the extracts of the test plants at different concentrations.

\begin{tabular}{llllllllll}
\hline Extract/Fungi & \multicolumn{3}{c}{ Ageratum houstonianum } & \multicolumn{3}{c}{ Eclipta prostrata } & \multicolumn{4}{c}{ Vitex negundo } \\
& $\mathbf{2 5 \%}$ & $\mathbf{5 0 \%}$ & $\mathbf{1 0 0 \%}$ & $\mathbf{2 5 \%}$ & $\mathbf{5 0 \%}$ & $\mathbf{1 0 0 \%}$ & $\mathbf{2 5 \%}$ & $\mathbf{5 0 \%}$ & $\mathbf{1 0 0 \%}$ \\
\hline Alternaria alternata & 52.92 & 72.92 & 87.92 & 19.51 & 44.39 & 73.65 & 12.31 & 14.39 & 18.04 \\
Aspergillus niger & 13.90 & 22.12 & 60.09 & 32.64 & 55.86 & 75.81 & 23.21 & 27.32 & 63.36 \\
Chaetomium funicola & 24.76 & 48.60 & 58.60 & 19.53 & 30.81 & 53.72 & 11.51 & 11.86 & 12.55 \\
Fusarium oxysporum & 28.82 & 45.37 & 77.13 & 16.82 & 20.58 & 24.70 & 42.95 & 53.81 & 77.08 \\
\hline
\end{tabular}

Aspergillus flavus was the most frequent isolated fungi having the highest frequency $3.64 \%$ followed by Alternaria alternata $3.51 \%$ and Aspergillus niger $3.43 \%$. The unidentified species of fungi were mostly isolated from seeds from village and all were present only on seeds treated with Sodium hypochlorite $(\mathrm{NaOCl})$. Due to their only occurrence in sterilized seeds it can be guesstimated that they might be pathogenic or seed- borne fungi rather than saprophytic. The genus Aspergillus, Penicillium, Mucor and Rhizopus were isolated from untreated seeds at a higher ratio as compared to treated seeds. This result predicts their saprophytic nature.

Among all extracts and fungi Ageratum houstonianum was most effective against Alternariaalternata at $100 \%$ concentration and the extract of Vitex negundo showed very less effect on mycellial inhibition of Chaetomium funicola. 


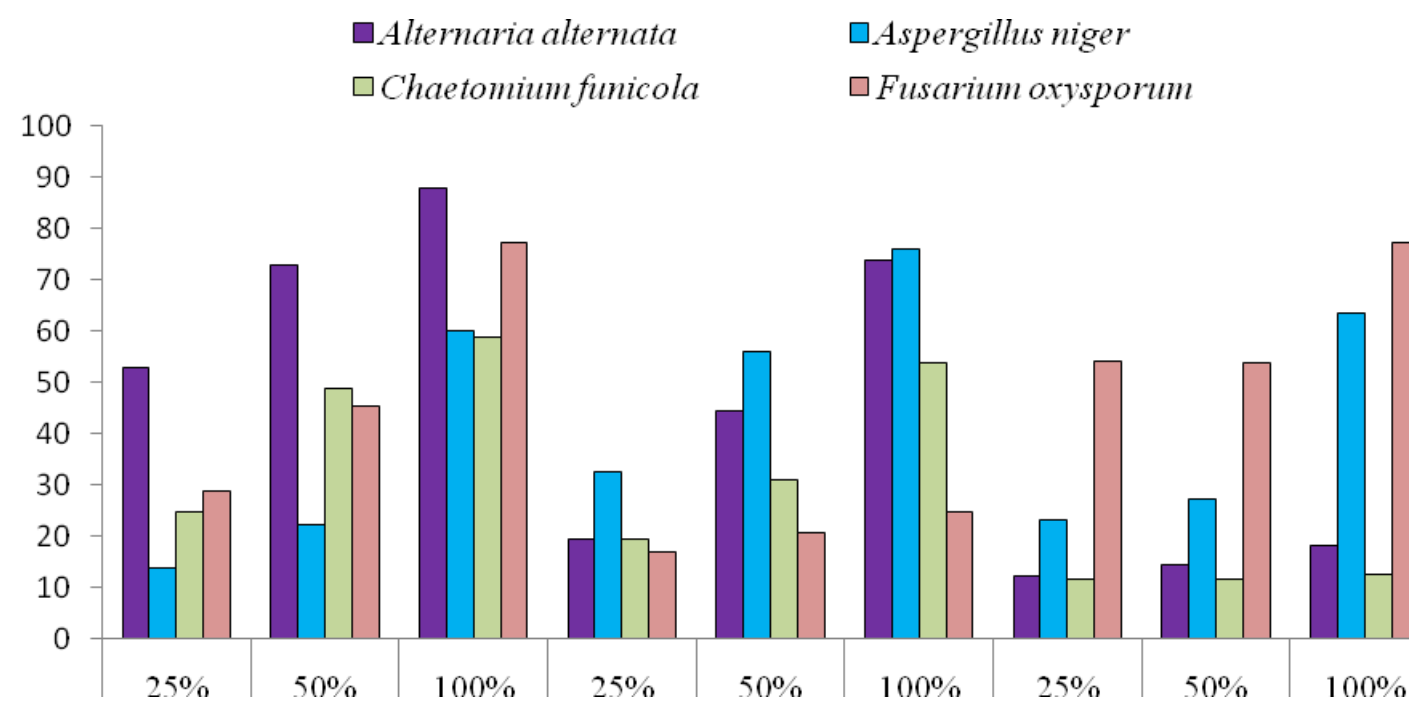

Fig. 6. Mean percentage inhibition of test fungi by plant extracts.

All the plant extract has shown inhibitory effect to all the test fungi on different extent, inhibition being best at $100 \%$ concentration.

Ageratum houstonianum was the most effective against the inhibition of Alternaria alternata followed by Fusarium oxysporum, Aspergillus niger and Chaetomium funicola. Similarly, Fusarium oxysporum was most sensitive to the acetone extract of whole plant of Ageratum conyzoides which was $84.21 \%$ inhibition, benzene extract $(3.94 \%)$, chloroform extract $(26.31 \%)$, ethyl acetate extract $(39.47 \%)$ and methanol extract (13.15\%) inhibition (Pal and Kumar 2013).

But Eclipta prostrata has shown best response to Aspergillus niger followed by Alternaria alternata, Chaetomium funicola and Fusarium oxysporum.

Similarly, the extract of Vitex negundo was best effective against Fusarium oxysporum followed by Aspergillus niger, Alternaria alternata and Chaetomium funicola. Mahmud et al. (2009) showed crude ethanolic extract of fruit (seeds) of Vitex negundo showed excellent result against Fsarium solani (90\%).
The result shows that Ageratum houstonianum as compared to other tested plants has a wider inhibition potentiality.

\section{REFERENCES}

Agrios, G.N. 2005. Plant Pathology (5 ${ }^{\text {th }}$ ed.). Burlington, MA, Elsevier Academic Press, USA.

Baka, Z.A.M.B. 2014. Plant extract control of fungi associated with different Egyptian wheat cultivars grains. Journal of Plant Protection Research 54(3):232-237.

Baka, Z.A.M.B., M. Serag and T.A. Kardosha. 2014. Mycoflora associated with some stored seeds and their control by aqueous extract from medicinal plants. Life Science Leaflets 57:49-62.

Barton, L.V. 1961. Seed Preservation and Longevity. Leonard Hill Books Limited, London.

Bass, L.N. 1973. Controlled atmosphere and seed storage. Seed Sci. and Technology, pp. 30-33. 
Burt, S. 2004. Essential oils: Their antibacterial properties and potential applications in foodsa review. International Journal of Food Microbiology 94:223-253.

Christensen, C.M. and H.H. Kaufmann. 1965. Deterioration of stored grain by fungi. Ann. Rev. Phytopath. 3:69-84.

Christensen, C.M. and H.H. Kaufmann. 1969. Role of Fungi in Quality Loss. Univ. of Minnesota Press, USA, 153 pp.

De Tempe, J. 1953. The blotter method of seed health testing. Proc. Int. Seed Test Ass. 28:133-151.

Delouche, J.C., R.K. Matthes, G.M. Dougherty and A.H. Boyd. 1973. Storage of seed in subtropical and tropical regions. Seed Sci. and Technol. 1:671-700.

Embaby, E.M. and M.A.G. Mona. 2006. Seed borne fungi and mycotoxins associated with some legume seeds in Egypt. Journal of Applied Sciences Research 2(11):1064-1071.

Embaby, E.M., R. Mohamed, M.A. AbdelWahhab, O. Hassan and M.M. Asmaa. 2013. Occurrence of toxigenic fungi and mycotoxins in some legume seeds. Journal of Agricultural Technology 9(1):151-164.

Ghosh, J., B. Nandi and N. Fries. 1981. Deterioration of stored wheat caused by fungal infections under different conditions of temperature and relative humidity. Ztschrift Pflanzenkrankh. U Pflanzenschutz. 88:9-17.

Grover, R.K. and J.D. Moore. 1962. Toximetric studies of fungicides against brown rot organism. Sclerotina fruticola. Phytopathology 52:876-880.

Harrington, J.F. 1972. Seed storage and longevity, (ed.) T.T. Kozlowskied. Seed Biology 3:145245.
Khalanguiset, P., G.S. Shephard and F. Wu. 2011. Aflatoxin and growth impairement. Critical Reviews in Toxicology 41:740-755.

Khan, A.B., F.U. Rahamn, I.U. Haque and M. Aslam. 1984. Seed-borne mycoflora of lentil. Pakistan J. Agric. Res. 5(3):160-161.

Lutey, R.W. and C.M. Chirstensen. 1963. Influence of moisture content, temperature and length of storage upon survival of fungi in Barley kernels. Phytopathology 53:713-717.

Mahmud S., H. Shareef, U. Farrukh, A. Kamil and G.R. Rizwani. 2009. Antifungal activities of Vitex negundo Linn. Pak. J. Bot. 41(1):19411943.

MOAD. 2011. Statstical Information of Nepalese Agriculture, 2010-11. Stastical Division, Agribusiness Promotion Centre, Ministry of Agriculture and Development, Hariharbhawan, Kathmandu.

Musket, A.E. 1948. Technique for the examination of seeds for the presence of seed-borne fungi. Trans. Br. Mycol. Soc. 30:74-83.

Nasir, N. 2003. Detecting seed borne fungi of soybean by different incubation methods. Plant Pathol. 2:114-118.

Neupane, R.K., A. Sharma, D. Aryal, R. Shah, S.R. Gupta and K. Maldonado. 2013. Technology demonstration and value chain interventions for commercial promotion of lentil in rice fallows in Terai of Nepal. Journal of International Developmant and Cooperation 20(3):29-43.

Nik, W.Z. 1980. Seed-borne fungi of soybean (Glycine $\max (\mathrm{L}$.$) Merril and their control.$ Pertanika 3(2):125-132.

Oyagade, J.O., J.T. Awotoye, A. Adewumi, H.T. Thrope. 1999. Antimicrobial activity of some Nigerian medicinal plants, screening for antibacterial activity. Journal of Bioscience Research Communication 11:193-197. 
Pal, G.K. and B. Kumar. 2013. Antifungal activity of some common weed extracts against wilt causing fungi, Fusarium oxysporum. Current Discovery 2(1):62-67.

Pandey, S.N., S.K. Dwivedi and R.S. Dwivedi. 1991. Microfungi associated with the stored seeds of lentil (Lens culinaris Medic). Proc. Nat. Acad. Sci. India 61(B):337-341.

Raju, S.M.R.H. 2013. Effect of Biotic and Abiotic Factors on the Quality of Lentil Seed Stored in Different Containers. MS Thesis, Department of Plant Pathology, Bangladesh Agricultural University, Mymensingh.

Rao, G.P. and A.K. Shrivastava. 1994. Toxixicty of essential oils of higher plants against fungal pathogens of sugarcane. Current Trend in Sugarcane Pathology. (eds.) Rao, G.P., A.G. Gillasple, P.P. Upadhaya, A. Bergamin, V.P. Agnihotri and C.T. Chen. International Books and Periodicals Supply Service, Pitampura, Delhi, pp. 347-365.
Rathod, L.R., M.D. Jadhav., S.K. Mane., S.M. Muley, P.S. Deshmukh. 2012. Seed borne mycoflora of legume seeds. International Journal of Advanced Biotechnology and Research 3(1):530-532.

Schmutter, H. 1990. Properties and potential of natural pesticides from the neem tree Azadirachta indica. Annual Review of Entomology 35:271-297.

Shah, R. and J.P. Jain. 1993. Seed mycoflora of mustard and it's control. Indian J. Mycol. and Plant Pathol. 23:291-295.

Sharma, S., A.N. Raghunathan and H.C. Shetty. 1988. Seed mycoflora of cow pea (Vigna ungicolota L. Walp) and their pathogenic importance. Seed Sci. and Tecnol. 16:541-548.

Warnock, D.W and T.F. Preece. 1971. Location and extent of fungal mycelium in grains of barely. Transactions of the British Mycological Society 56:267-273. 